\title{
PLASMOCITOMA ÓSSEO SOLITÁRIO EM CÃES: RELATO DE TRÊS CASOS
}

\author{
SOLITARY OSSEOUS PLASMOCYTOMA IN DOGS: A REPORT OF THREE CASES
}

\author{
R. BARROCO-NETO ${ }^{1}$, C. R. MELLO ${ }^{1}$, A. G. ROCHA ${ }^{1}$, G. SEMBENELLI ${ }^{2}$, \\ F.A.R. SUEIRO ${ }^{3}$, P. C. JARK ${ }^{*}$
}

\begin{abstract}
RESUMO
O plasmocitoma ósseo solitário é uma neoplasia incomum, não secretória que pode acometer tanto o esqueleto apendicular como o axial. Os sinais clínicos dos plasmocitomas ósseos incluem dor, claudicação e alterações neurológicas relacionadas à compressão medular. A suspeita diagnóstica é baseada na avaliação radiográfica caracterizada por lesões ósseas líticas e a confirmação diagnóstica é realizada por meio do exame histopatológico, sendo o mieloma múltiplo um dos principais diagnósticos diferenciais. $\mathrm{O}$ tratamento para pacientes portadores de plasmocitoma ósseo solitário incluem cirurgias, radioterapia ou ainda tratamento paliativo direcionado para o controle da dor óssea quando a cirurgia não for uma opção viável. O objetivo do presente relato é descrever três casos de plasmocitomas ósseos solitários em cães sendo dois em vértebras lombares, que foram submetidos à remoção cirúrgica e que tiveram boa resposta ao tratamento empregado. Apesar de pouco descrito na literatura, o plasmocitoma ósseo solitário é um importante diferencial para lesões líticas em cães e pode apresentar tempo livre de progressão de doença e sobrevidas superiores a outras neoplasias ósseas como osteossarcoma quando submetidos ao tratamento adequado.
\end{abstract}

PALAVRAS-CHAVE: neoplasia óssea, oncologia, osteólise, plasmócitos.

\section{SUMMARY}

Solitary osseous plasmocytoma (SOP) is an uncommon, non-secretory neoplasm that can affect both the appendicular and axial skeletons. Clinical signs of bone plasmocytomas include pain, lameness and neurological changes related to spinal cord compression. The diagnosis is based on radiographic evaluation characterized by lytic bone lesions and confirmation is through histopathological examination, with multiple myeloma being one of the main differential diagnoses. Treatment of patients with SOP includes surgery, radiation therapy or palliative treatment directed at bone pain control when surgery is not a viable option. The objective of the present report is to describe three cases of SOP, two in lumbar vertebrae that were submitted to surgical removal with good response to the treatment. Although less described in the literature, SOP is an important differential for lytic lesions in dogs and may present disease free interval and survival time superior to other bone neoplasms such as osteosarcoma when submitted to adequate treatment

KEY-WORDS: bone neoplasia, oncology, osteolysis, plasma cell.

\footnotetext{
${ }^{1}$ Universidade Brasil - Descalvado - SP

${ }^{2}$ Médico veterinário autônomo.

${ }^{3}$ Laboratório VETPAT - Campinas - SP.

* Autor para correspondência. - paulocjark@ hotmail.com - Av. Hilário de Passos, 950 - Descalvado - SP
} 


\section{INTRODUÇÃO}

As desordens oncológicas relacionadas aos plasmócitos descritas em veterinária compreendem um grupo de afecções com comportamento clínico altamente variável e estão entre estas: o mieloma múltiplo, plasmocitoma ósseo solitário, plasmocitomas extramedulares (subdivididos em cutâneos e não cutâneos) e, menos comumente, as leucemias de plasmócitos e a macroglobulinemia de Waldenström's (HAYES et al., 2007; GORENSTEIN et al., 2016 ).

O plasmocitoma ósseo solitário é uma neoplasia incomum, não secretória que pode acometer tanto o esqueleto apendicular como o axial. Os sinais clínicos dos plasmocitomas ósseos são dependentes do osso envolvido sendo que quando localizado em vértebras os sinais mais frequentes incluem dor e alterações neurológicas relacionadas à compressão de medula espinhal enquanto que nos casos de plasmocitoma apendicular os principais sinais são dor, claudicação e ocorrência de fraturas patológicas (VAIL et. al. 2012).

A suspeita diagnóstica do plasmocitoma ósseo solitário é baseada na avaliação radiográfica caracterizada por lesões ósseas líticas algumas vezes em aspecto de "punched-out" e a confirmação se por meio do exame histopatológico. Os principais diagnósticos diferenciais incluem osteomielites fúngicas, bacterianas e outras neoplasias ósseas primárias ou metastáticas (RUSBRIDGE et al, 1999). No exame histopatológico a diferenciação entre plasmocitoma ósseo solitário e o mieloma múltiplo pode ser difícil, uma vez que ambos envolvem a proliferação de plasmócitos, sendo a primeira a forma localizada da doença, não secretória na maioria das vezes e a segunda caracterizada pela proliferação de plasmócitos na medula óssea com secreção concomitante de imunoglobulinas.

O tratamento para pacientes portadores de plasmocitoma ósseo solitário inclui cirurgias, radioterapia ou ainda tratamento analgésico e controle da reabsorção óssea com a administração de bisfosfonatos (VAIL et. al. 2012). O objetivo do presente relato é descrever três casos de plasmocitomas ósseos solitários que foram submetidos à remoção cirúrgica e que tiveram boa resposta ao tratamento empregado uma vez que é uma neoplasia de ocorrência incomum, portanto pouco descrita na literatura.

\section{Caso 1}

Cão, fêmea castrada, 11 anos, sem raça definida, foi encaminhado ao Hospital Veterinário da Universidade Brasil - campus Descalvado com histórico de relutância em caminhar e paraplegia de membros pélvicos. Durante o exame físico não foram identificadas alterações e no exame neurológico o animal apresentava dor a palpação de coluna em região lombar e déficit proprioceptivo em membros pélvicos. Os exames laboratoriais de hemograma e bioquímico (creatinina, ALT, proteína total e albumina) não apresentavam alterações. Como exame complementar, foi realizada radiografia da região, que foi sugestiva de uma possível discoespondilite. Para melhor caracterização da afecção em coluna foi realizada tomografia computadorizada em busca de maiores detalhes que pudessem auxiliar no diagnóstico. $\mathrm{O}$ exame tomográfico demonstrou presença de osteólise em lâmina vertebral da quinta vértebra lombar, pouco delimitável, apresentando contornos irregulares (Figura 1). Os demais corpos vertebrais estavam íntegros e alinhados.



Figura 1 - O exame tomográfico com presença de osteólise em lâmina vertebral da quinta vértebra lombar, pouco delimitável, apresentando contornos irregulares 
Foi prescrito tratamento analgésico com tramadol $4 \mathrm{mg} / \mathrm{kg}$ - TID - VO, dipirona $25 \mathrm{mg} / \mathrm{kg}$ TID - VO, gabapentina $5 \mathrm{mg} / \mathrm{kg}$ - VO - SID e infusão de pamidronato $2 \mathrm{mg} / \mathrm{kg}$ - IV diluído em solução fisiológica $0,9 \%$ administrado durante 2 horas em dose única. $\mathrm{O}$ animal foi submetido ao procedimento cirúrgico de laminectomia dorsal modificada para descompressão e coleta de material para análise histo patológica. No exame histopatológico foi evidenciada neoplasia maligna invadindo e permeando trabéculas ósseas, caracterizada por células redondas de padrão monótono, com núcleos pequenos e médios, hipercorados, presença de binucleações, com citoplasma moderadamente eosinofílico, confirmando a origem plasmocitária (Figura 2).

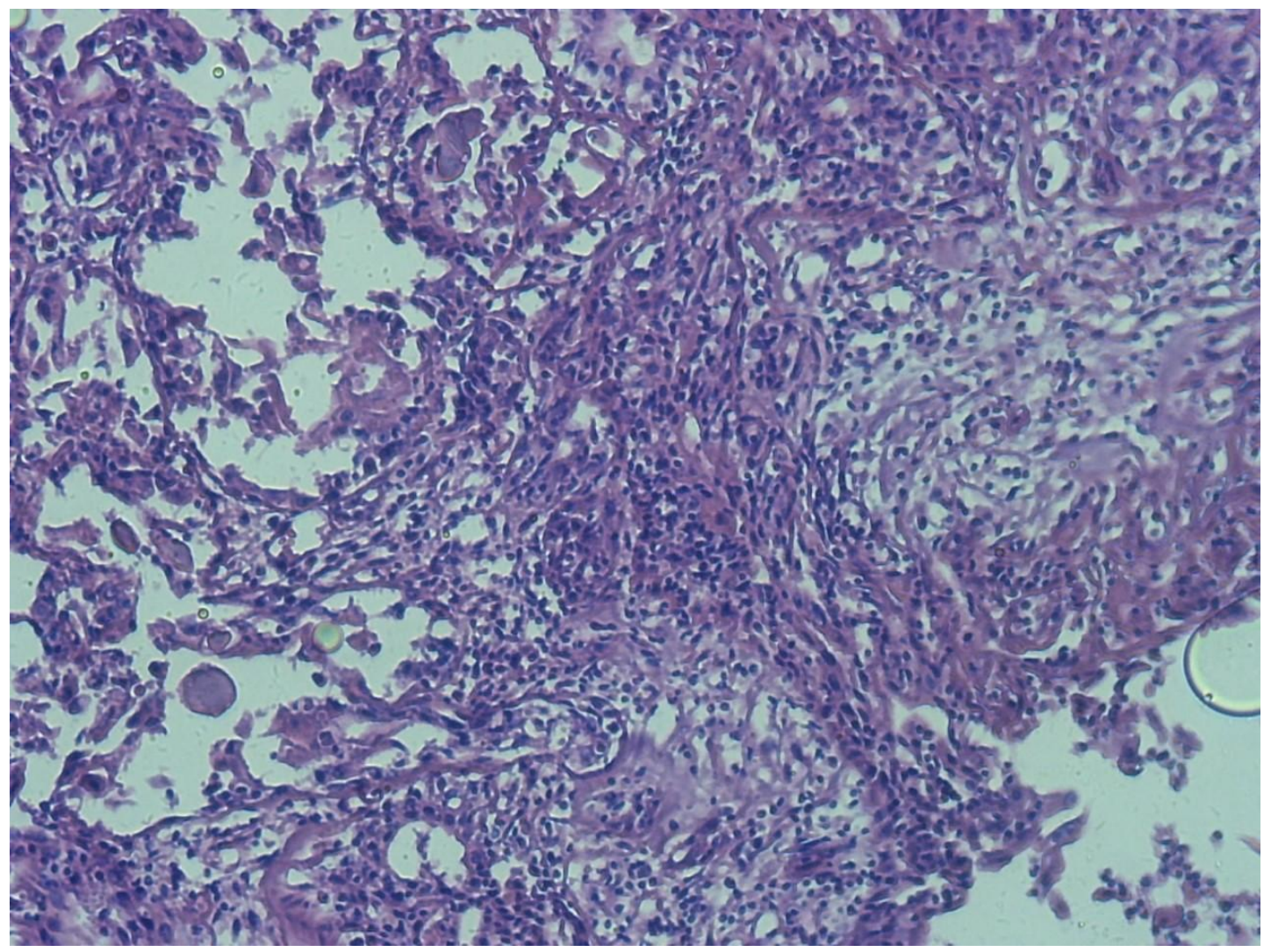

Figura 2 - Neoplasia maligna invadindo e permeando trabéculas ósseas, caracterizada por células redondas de padrão monótono, com núcleos pequenos e médios, hipercorados, com citoplasma moderadamente eosinofílico e presença de células binucleadas, confirmando a origem plasmocitária

Para diferenciação entre um quadro de mieloma múltiplo e plasmocitoma ósseo solitário foi recomendada a realização de punção de medula óssea associada a dosagem de globulinas com posterior eletroforese de proteína, porém o proprietário autorizou apenas a realização da dosagem de globulinas que se encontrava dentro dos valores de normalidade $(4,3 \mathrm{~g} / \mathrm{dl}$ - referência 2,7-4,4 g/dl). Devido ao fato do animal não apresentar lesões múltiplas nos exames de imagem, não apresentar hiperglobulinemia foi firmado o diagnóstico de plasmocitoma ósseo solitário e instituído o tratamento adjuvante.

Devido à ausência de margem cirúrgica e possibilidade de recidiva local foi optada pela realização de quimioterapia com melfalano (Alkeran ${ }^{\circledR}$ - Laboratório GSK) em regime de pulsoterapia $\left(7 \mathrm{mg} / \mathrm{m}^{2}\right.$ - VO- SID por 5 dias consecutivos a cada 21 dias). $\mathrm{O}$ animal recebeu quimioterapia por um período de 360 dias conforme anteriormente descrito, porém o proprietário após esse período optou por descontinuar o tratamento e realizar apenas o acompanhamento da paciente por meio de exames hematológicos e dosagens de globulinas seriadas a cada 21 dias e controle radiográfico da lesão em coluna. $\mathrm{O}$ animal não apresentou efeitos adversos significativos durante a quimioterapia apenas quadros de trombocitopenia grau I que não interferiram na continuação da terapia. Até o presente momento apresenta tempo livre de progressão de doença de 540 dias.

\section{Caso 2}

Cão, macho inteiro, 7,5 anos, sem raça definida, foi encaminhado ao Hospital Veterinário da Universidade Brasil- campus Descalvado com histórico de ataxia em membros pélvicos, seguidas de diminuição de reflexos proprioceptivos. O exame neurológico associado a palpação local sugeriam lesão em localização lombar. A principal suspeita inicial foi de discopatia, portanto foi realizada inicialmente como exame de triagem a radiografia da coluna vertebral na região toracolombar. Nas imagens, foi possível observar lise óssea extensa em terceira vertebra 
lombar, sugestiva de processo neoplásico ou infeccioso (Figura 3). Os exames laboratoriais de hemograma e bioquímico (creatinina, ALT, proteína total e albumina) não apresentavam alterações. $\mathrm{O}$ animal foi submetido a controle de dor com administração de tramadol na dose de $4 \mathrm{mg} / \mathrm{kg}$ - TID - VO associado previcox $5 \mathrm{mg} / \mathrm{kg}$ - VO - SID. Devido à paraparesia apresentada pelo paciente, ele foi submetido ao tratamento cirúrgico para descompressão da medula espinhal e uma amostra do material foi coletada e encaminhada para o histopatológico, com diagnóstico de plasmocitoma ósseo/mieloma múltiplo. Embora não tenha sido realizada a punção de medula óssea, os exames hematológicos e dosagens de globulinas não demostraram alterações sugestivas de hiperglobulinemia e associada ao fato da lesão ser localizada em apenas uma vértebra foi firmado o diagnóstico de plasmocitoma ósseo solitário. O proprietário optou por não realizar a quimioterapia para controle local da doença e o animal apresentou uma sobrevida de 1,095 dias vindos a óbito devido a causas não estabelecidas.

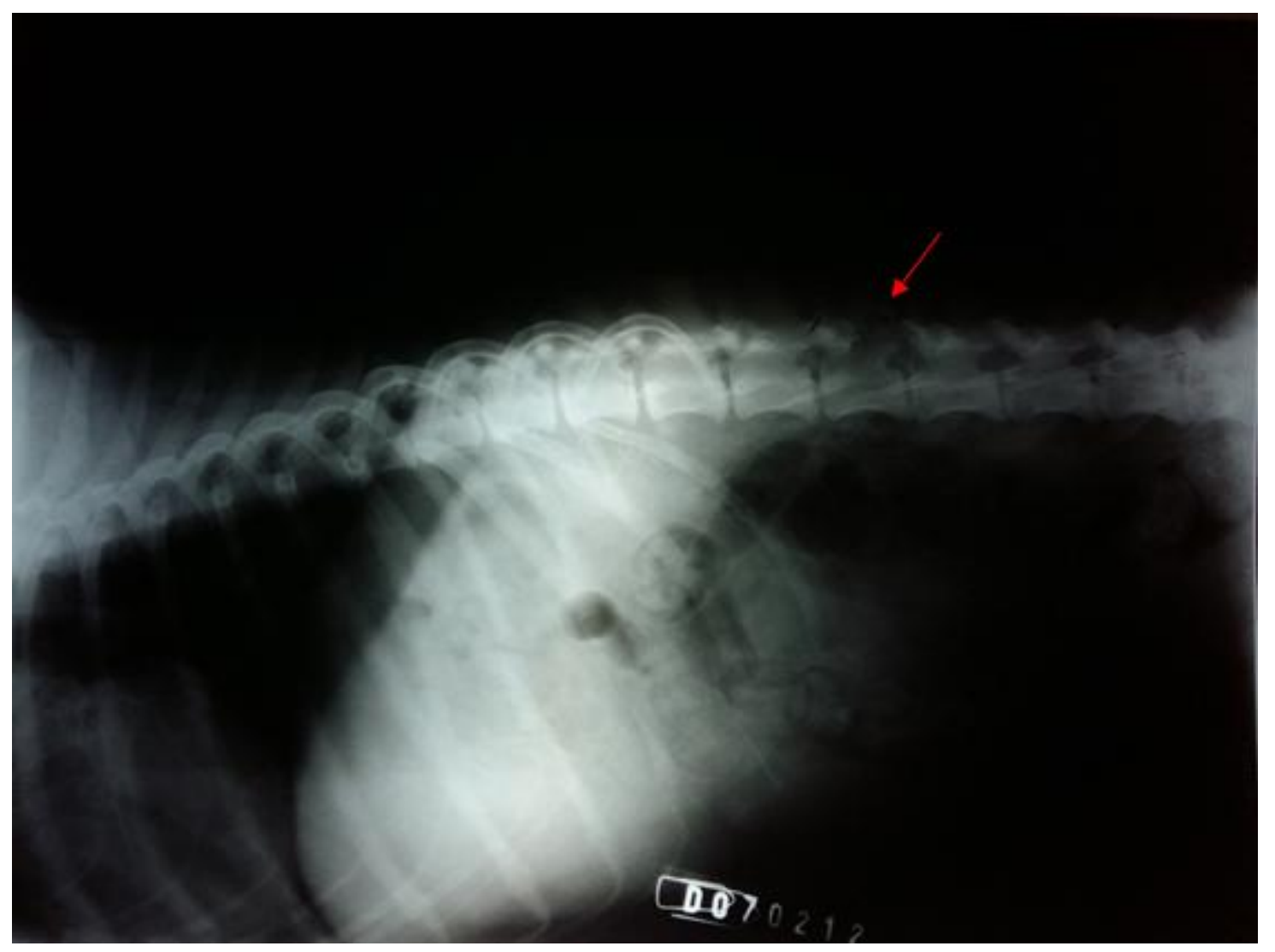

Figura 3 - Processo osteolítico observado em lamina e pedículo da terceira vertebra lombar (seta vermelha).

\section{Caso 3}

Cão, fêmea, 3 anos, Golden Retriever, foi encaminhado com histórico de hiperagesia, claudicação e aumento de volume em membro torácico esquerdo na porção distal de úmero.

O animal foi submetido a radiografia da região afetada em que foi visualizada uma área de lise óssea em formato de "punched out" (Figura 4). O animal foi submetido à biopsia incisional óssea que foi sugestiva de neoplasia de plasmócitos (plasmocitoma ósseo/mieloma múltiplo). Foram realizados demais exames bioquímicos para avaliação da possibilidade de hiperglobulinemia, porém devido aos valores normais, se suspeitou da forma localizada da doença. O proprietário não autorizou a realização de punção de medula óssea para avaliação do envolvimento sistêmico.

Inicialmente foi realizado apenas tratamento paliativo com analgésicos, pois o tutor do animal não autorizou a realização de amputação do membro nem a administração de pamidronato. Foi prescrito tramadol na dose de $5 \mathrm{mg} / \mathrm{kg}$ - TID, VO, dipirona na dose de 25 $\mathrm{mg} / \mathrm{kg}$, TID - VO e gabapentina na dose de $5 \mathrm{mg} / \mathrm{kg}-$ SID, VO como analgésicos. Após 14 dias do início do tratamento o animal retornou com progressão da lesão, não apoiava mais o membro e o aumento de volume estava mais evidente. $O$ tutor então optou pela amputação do membro como forma de promover qualidade de vida para o paciente.

Devido à obtenção de margem cirúrgica com a amputação do membro, não foi indicada a quimioterapia para controle local da doença, porém o tutor foi orientado sobre a possibilidade de desenvolvimento de mieloma múltiplo e explicado que não há informações na literatura sobre os benefícios do melfalano na prevenção da evolução da forma solitária (plasmocitoma ósseo solitário) para a forma sistêmica da doença (mieloma múltiplo). 


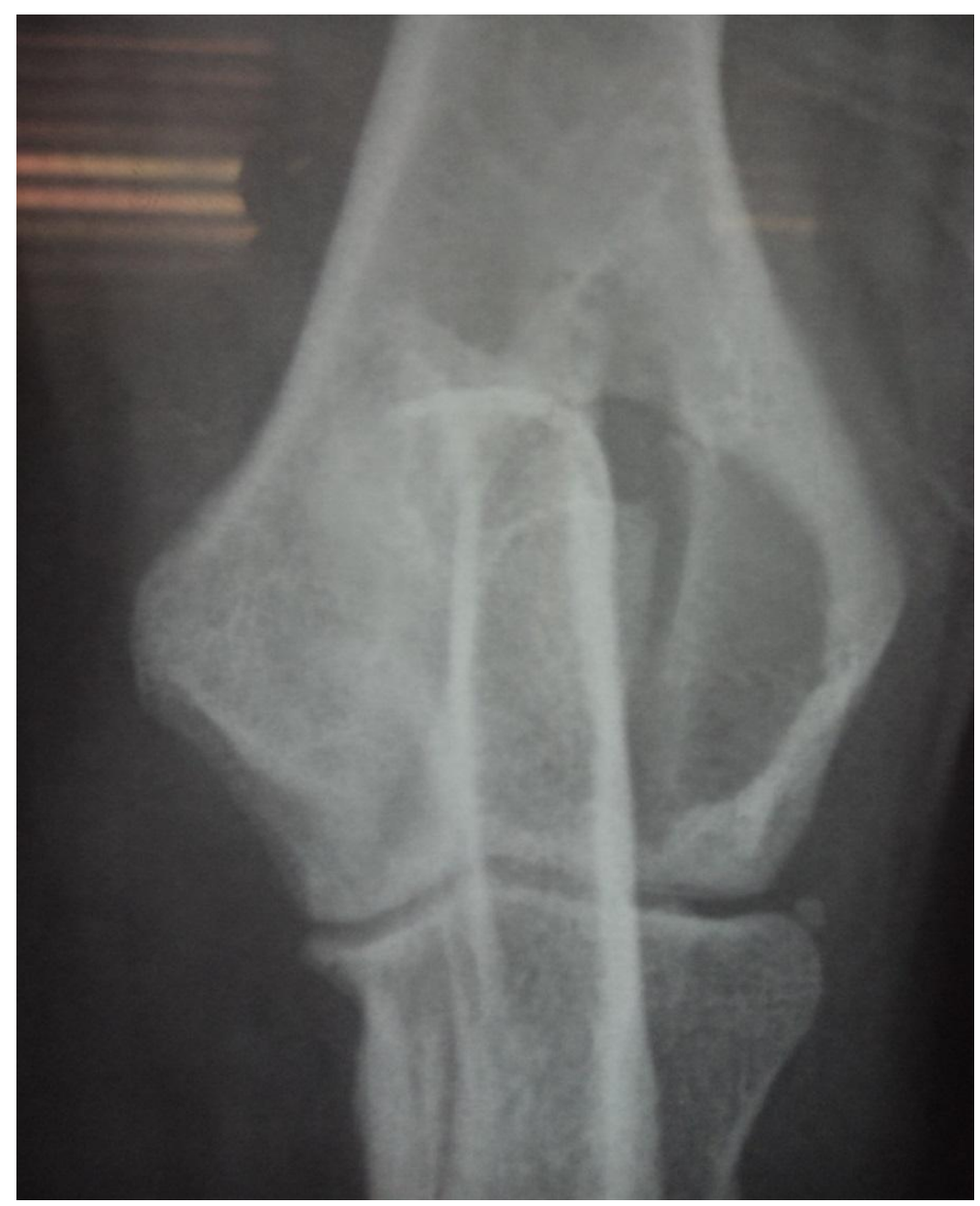

Figura 4 - Lesão lítica em “punched out” em região de epicôndilo de úmero esquerdo.

Após a realização do procedimento cirúrgico, o animal apresentou boa recuperação, porém após a retirada dos pontos o tutor não compareceu nos retornos solicitados para avaliação da evolução do caso. Foi realizado contato telefônico com o mesmo que informou que o animal veio a óbito aproximadamente 11 meses após a realização da cirurgia, porém a causa do óbito não foi estabelecida.

\section{DISCUSSÃO}

O plasmocitoma ósseo solitário é uma desordem incomum de plasmócitos que pode afetar tanto o esqueleto apendicular como o axial (VAIL et. al. 2012). No presente relato dois casos afetaram as vértebras lombares e um caso afetou o membro torácico esquerdo.

Os sinais clínicos de dor à palpação na região da coluna associados a déficit neurológico apresentados pelos animais do presente relato estão de acordo com o estudo de Rusbridge et al, (1999) que relataram oito casos de plasmocitomas ósseos em vértebras e todos os animais apresentam esses sinais clínicos citados.

A apresentação radiográfica e tomográfica dos casos apresentados está em concordância com as alterações ósseas encontradas em pacientes com desordens de plasmócitos do estudo de Rusbridge et al,
(1999) em que todos os animais apresentaram lesões líticas e em 5/8 dos casos essas eram solitárias como no presente relato. $\mathrm{O}$ animal do caso 3 apresentou lesão em "punched out" que é caracterizada por lesões líticas circulares que podem ser solitárias ou múltiplas que é altamente sugestiva de distúrbios plasmocitários como mieloma e plasmocitoma ósseo solitário.

Os principais diferenciais para lesões ósseas líticas incluem osteomielites fúngicas, bacterianas ou secundárias a leishmaniose, neoplasias ósseas primárias e metastáticas e cistos ósseos (JOHNSON et al, 2003; LAMAGNA et al, 2006; SCHULTZ et al, 2007; FARESE et al, 2009; TROST et al, 2014).

As osteomielites fúngicas mais frequentemente citadas na literatura incluem blastomicose e coccidioidomicose, porém as mesmas são raras ou não acontecem em determinadas regiões do Brasil (JOHNSON et al, 2003; DEUS-FILHO et al. 2010). As osteomielites bacterianas normalmente estão associadas a lesões de continuidade como traumas, cirurgias ortopédicas, mordidas ou ferimentos. Nenhum animal do presente relato apresentava qualquer uma dessas alterações. As osteomielites secundárias a leishmaniose são incomuns. Agut et al, (2003) relataram vinte e seis casos de alterações ósseas e articulares em cães com leishmaniose, sendo que os ossos longos foram os mais afetados e a forma bilateral a mais comum. O padrão radiográfico mais comum foi 
de proliferação periosteal e intramedular principalmente envolvendo a diáfise e em menor proporção lesões líticas. Os animais do estudo de Agut et al. (2003) apresentavam outros sinais clínicos relacionados a leishmaniose além das alterações ósseas, apresentavam exame histopatológico com identificação do agente e nenhum animal apresentou envolvimento de vértebras como nos casos relatado no presente estudo.

Em relação às principais neoplasias ósseas primárias destacam-se o osteossarcoma e o condrossarcoma que apesar de normalmente se apresentarem como lesões mistas tanto líticas como proliferativas eventualmente podem ser caracterizados por lesões exclusivamente líticas (FARESE et al, 2009). Outras neoplasias ósseas primárias que podem levar a lesões ósseas líticas incluem sarcomas histiocíticos, hemangiossarcomas e linfomas ósseos, porém a incidência dessas neoplasias é baixa (LAMAGNA et al, 2006; SCHULTZ et al, 2007).

As neoplasias ósseas metastáticas mais comumente vistas em animais incluem os carcinomas prostáticos, de bexiga, de saco anal e em menor incidência os carcinomas mamários e de origem desconhecida embora neoplasias em outras regiões possam causar metástase óssea (TROST et al, 2014; ROSSI et al, 2015).

A ocorrência de lesões ósseas benignas como osteomas e cistos ósseos também são relatados (EHEHART et al, 2012). Os osteomas normalmente se apresentam como lesões proliferativas, bem circunscritas o que difere dos animais do presente relato que apresentavam lesões exclusivamente líticas. O cisto ósseo é um importante diferencial principalmente para o caso 3 , pois esses normalmente acometem animais mais jovens e se apresentam como lesões circulares radioluscentes em ossos longos, embora a forma multilocular seja mais frequente que a solitária. A diferenciação dessas duas alterações pode ser realizada pelo exame histopatológico (EHEHART et al, 2012).

O diagnóstico diferencial de mieloma múltiplo nos casos apresentados foi realizado através da detecção de uma lesão óssea solitária associada ao fato de não haver hiperglobulinemia (VAIL et al, 2012). A realização de mielograma seria importante na caracterização exata do quadro, porém essa não foi autorizada pelos tutores. A ocorrência de mielomas múltiplos não secretórios são extremamente raras na medicina veterinária com poucos relatos descritos na literatura (MARKS et al, 1995). No caso 2 o fato do animal não ter realizado nenhum tratamento além da remoção cirúrgica e apresentar sobrevida superior a um ano confirma o diagnóstico de plasmocitoma ósseo solitário, pois nos casos de mieloma múltiplo sem tratamento quimioterápico a sobrevida seria provavelmente inferior.

A realização de quimioterapia no caso 1 foi baseada principalmente nas chances de recidiva local, uma vez que não existem dados na literatura mostrando que a realização dessa modalidade terapêutica diminui a progressão para mieloma meses ou anos após o diagnóstico inicial (VAIL et al, 2012). O melfalano é o agente de escolha para o tratamento de desordens de plasmócito em cães principalmente de animais acometidos por mieloma múltiplo, pois interfere na proliferação de plasmócitos auxiliando dessa forma no controle da doença, diminuindo os níveis de globulinas e auxiliando no remodelamento ósseo e controle de dor além de ser bem tolerado pelos cães.

O objetivo da instituição da quimioterapia no paciente do caso 1 foi o controle de doença local uma vez que devido à localização em vértebra a margem cirúrgica não pode ser obtida. Não há dados na literatura que essa o uso de melfalano auxilie no controle local da doença, porém o paciente do presente estudo apresenta até o momento tempo livre de progressão de doença de 540 dias, sugerindo um efeito benéfico do melfalano nessa situação. Os principais afeitos adversos do melfalano em cães estão relacionados à mielossupressão principalmente trombocitopenia. Apesar do paciente do caso 1 apresentar quadros de trombocitopenia grau I ao longo do tratamento, o protocolo de pulsoterapia foi bem tolerado (VAIL et al. 2012)

Antes do procedimento cirúrgico todos os animais foram submetidos a tratamento analgésico devido à dor causada pela lise óssea. O paciente do caso 1 recebeu concomitantemente pamidronato que é um bisfosfonato que auxilia no controle de reabsorção óssea através da apoptose de osteoclastos contribuindo tanto para o remodelamento ósseo, prevenção de fraturas patológicas e redução da dor causada pela osteólise (JARK et al. 2013).

O prognóstico de cães com plasmocitoma ósseo solitário é variável, sendo que nos cães que evoluem para mieloma múltiplo o prognóstico é considerado reservado uma vez que a presença de áreas de osteólise é considerada fator prognóstico negativo em animais com mieloma (VAIL et al, 2012). O animal do caso um apresenta remissão completa de 18 meses até o momento não apresentando sinais de hiperglobulinemia ou outros focos de lise óssea que sugerem evolução do quadro para a forma sistêmica da doença. Os animais dos casos 2 e 3 apresentaram sobrevidas de aproximadamente 36 e 11 meses respectivamente sem tratamento quimioterápico adjuvante e vieram a óbito por causas não estabelecidas sugerindo que os plasmocitomas ósseos solitários podem apresentar sobrevidas longas apenas com o tratamento cirúrgico local.

\section{CONCLUSÃO}

Apesar de pouco descrito na literatura, o plasmocitoma ósseo solitário é um importante diferencial para lesões ósseas líticas em cães. A diferenciação entre o plasmocitoma ósseo solitário e o mieloma múltiplo é de suma importância, pois são desordens plasmocitárias com tratamentos e prognósticos distintos. A definição correta do diagnóstico associado ao tratamento cirúrgico e terapias adjuvantes pode proporcionar tempo livre de progressão de doença superiores a outras neoplasias ósseas primárias, como nos casos relatados. 


\section{REFERÊNCIAS}

AGUT, N.; CORZO, J.; MURCIANO, F. G. Clinical and radiographic study of bone and joint lesions in 26 dogs with leishmaniasis. Veterinary Record. v.153, p.648-652, 2013.

DEUS-FILHO, A.; DEUS, A. C. B.; MENESES, A. O.; SOARES, A. S.; LIRA, A. L. A. Manifestações cutâneo-mucosas da coccidioidomicose: estudo de trinta casos procedentes dos estados do Piauí e Maranhão. An. Bras. Dermatol. v.85, n.1,p.45-51. 2010

EHRHART, N.P.; RYAN, S.D.; FAN, T.M. Tumor of skeletal system In: WITHROW, S.; PAGE, R .Small Animal Clinical Oncology. 2009, 5.ed. p.463-503.

FARESE, J. P.; KIRPENSTEIJN, J.; KIK, M.; BACON, N. J.; WALTMAN, S. S.; SEGUIN, B.; KENT, M.; LIPTAK, J.; STRAW, R.; CHANG, M. N.; JIANG, Y.; WITHROW, S. J. Biologic behavior and clinical outcome of $25 \mathrm{dogs}$ with canine appendicular chondrosarcoma treated by amputation: a Veterinary Society of Surgical Oncology retrospective study. Veterinary Surgery, v.38, p.914-919, 2009.

GORENSTEIN, T. G.; JARK, P. C.; FELICIANO, M. A. R.; SUEIRO, F. A. R.; ANAI, L. A.; FENERICH, M., SENHORELLO, I. S.; RODRIGUES, B. C.; TINUCCI-COSTA, M. Extramedullary plasmacytoma in the penile bulb of a dog: case report. Arquivo Brasileiro de Medicina Veterinária e Zootecnia. v.68, n.2, p.292-298, 2016

HAYES, A. M.; GREGORY, S. P.; MURPHY, S.; MCCONNEL, J. F.; PATTERSON-KANE, J. C. Solitary extramedullary plasmacytoma of the canine larynx. J Small Anim Pract. v.48, p.288-291, 2007.

JARK, P. C.; DE NARDO, C. D. D.; BERNABÉ, C. G.; PEREIRA, D. C. L.; CAVALLINI, E. M.; ANDRADE, M. G.; BORTOLI, R. C.; TINUCCICOSTA, M.; DE NARDI, A, B. Emprego dos bisfosfonatos em oncologia veterinária. Veterinária e Zootecnia. v.20, p.404-415, 2013

JOHNSON, L. R.; HERRGESELL, E. J.; DAVIDSON, A. P. 2013. Clinical, Clinicopathologic, And Radiographic Findings In Dogs With Coccidioidomycosis: 24 Cases (1995-2000). Journal of Veterinary Animal Hospital Association v.222. p.461-466, 2013.
LAMAGNA, B.; LAMAGNA, F.; MEOMARTINO, L.; PACIELlO, O.; FATONE, G. Polyostotic Lymphoma With Vertebral Involvement and Spinal Extradural Compression in a Dog. Journal of Veterinary Animal Hospital Association. v.42, p.7176, 2006.

MARKS, S. L.; MOORE, P. F.; TAYLOR, D. W.; MUNN, R. J. Nonsecretory Multiple Myeloma in a Dog: Immunohistologic and Ultrastructural Observations. Journal of Veterinary Internal Medicine. v.19, p.50-54, 1995.

ROSSI, F.; ARESU, L.; VIGNOLI, M.; BURACCO, P.; BETTINI, G.; FERRO S.; GATTINO, F.; GHIANI, F.; COSTANTINO, R.; RESSEL, L.; BELLEI, E.; MARCONATO L. Metastatic cancer of unknown primary in 21 dogs. Veterinary Comparative Oncololy, v.13, p.11-13, 2015

RUSBRIDGE, C.; WHEELER, S. J.; LAMB, C. R.; PAGE, R. L.; CARMICHAEL, S.; BREARLEY, M. J.; BJORNSON, A. P. Vertebral Plasma Cell Tumors in 8 Dogs. Journal of Veterinary Internal Medicine. v.13, p.126-133, 1999.

SCHULTZ, R. M; PUCHALSKI, S. M.; KENT, M.; MOORE, P. F. Skeletal Lesions Of Histiocytic Sarcoma In Nineteen Dogs. Veterinary Radiology and Ultrassound. v.48 p.539-543, 2007.

TROST, M. E.; INKELMANN, M. A.; GALIZA, G. J. N.; SILVA, T. M.; KOMMERS G. D. Occurrence of Tumours Metastatic to Bones and Multicentric Tumours with Skeletal Involvement in Dogs. Journal of Comparative Oncology, v.150, p.8-17, 2014

VAIL, D. M.; PINKERTON, M. E.; YOUNG K. M. 2009. Hematopoietic Tumours In: WITHROW, S. PAGE, R .Small Animal Clinical Oncology. 2009, 5ed. p.665-679. 